\title{
Induction of Cytosolic Phosphoenolpyruvate Carboxykinase in the Ovine Fetal Liver by Chronic Fetal Hypoglycemia and Hypoinsulinemia $^{1}$
}

\author{
MICHAEL R. NARKEWICZ, THOMAS D. CARVER, AND WILLIAM W. HAY, JR \\ Division of Pediatric Gastroenterology and Nutrition [M.R.N.] and Division of Perinatal Medicine and Research \\ [T.D.C., W.W.H.], Department of Pediatrics, University of Colorado School of Medicine,
}

Denver, Colorado 80262

\begin{abstract}
Fetal glucose production has been observed in the chronically hypoglycemic, hypoinsulinemic (HH) fetal lamb. The purpose of this study was to test the hypothesis that induction of hepatic gluconeogenic enzymes occurs in this condition. The activities of both mitochondrial and cytosolic phosphoenolpyruvate carboxykinase (PEPCK), fructose-1,6-diphosphatase, and glucose6-phosphatase, three key enzymes of gluconeogenesis, were determined in fetal sheep liver from HH lambs and controls (CONT). Pregnant ewes were maintained chronically hypoglycemic by continuous hyperinsulinemic clamps from approximately $80 \mathrm{~d}$ of gestational age $(53 \%$ of gestation) for 6 wk. Fetuses (gestational age: $\mathbf{H H}=136 \pm$ $2.6, \mathrm{CONT}=133 \pm 3.7 \mathrm{~d}$ ) were maintained chronically hypoglycemic $[\mathrm{HH}=0.51 \pm 0.05$ versus $\mathrm{CONT}=1.22 \pm$ $0.11 \mathrm{mmol} / \mathrm{L}(9.2 \pm 1.0$ versus $21.9 \pm 11.9 \mathrm{mg} / \mathrm{dL})]$ and hypoinsulinemic $(\mathrm{HH}=3.3 \pm 0.6$ versus $\mathrm{CONT}=12.0 \pm$ $2.2 \mu \mathrm{U} / \mathrm{mL}$ ) and delivered by cesarean section after measurement of fetal glucose production rate. Hepatic cytosolic PEPCK was $6.0 \pm 1.4 \mathrm{nmol} / \mathrm{min} / \mathrm{mg}$ protein in CONT and $19.7 \pm 2.5$ in $\mathrm{HH}$ lamb $(p<0.05)$, whereas mitochondrial PEPCK was not different between the two groups. Neither fructose-1,6-diphosphatase or glucose-6-phosphatase activities nor plasma glucagon levels were different between groups. These results suggest that chronic fetal hypoglycemia and hypoinsulinemia prematurely induce hepatic cytosolic PEPCK in the fetal lamb. The observed fetal glucose production in the $\mathrm{HH}$ fetal lamb may be due to gluconeogenesis. (Pediatr Res 33: 493-496, 1993)
\end{abstract}

\section{Abbreviations}

PEPCK, phosphoenolpyruvate carboxykinase G-6-Pase, glucose-6-phosphatase

HH, hypoglycemic, hypoinsulinemic

FDPase, fructose-1,6-diphosphatase

Hepatic gluconeogenesis does not occur at significant rates in the unstressed fetal sheep (1). After birth, the newborn must

Received May 19, 1992; accepted December 17, 1992.

Correspondence: Michael R. Narkewicz, M.D., Childrens Hospital B290, Section of Pediatric Gastroenterology and Nutrition, 1056 East 19th Ave., Denver, CO 80218.

Supported in part by National Institutes of Health Grant HD 20761. T.D.C. is supported by the United States Army.

${ }^{1}$ The opinions expressed herein are those of the authors and do not necessarily represent those of the US Army or the Department of Defense. eventually develop gluconeogenic potential to maintain glucose homeostasis. Several studies have demonstrated that the development of hepatic gluconeogenesis is correlated with the appearance of cytosolic PEPCK (EC 4.1.1.32), the rate-limiting enzyme in gluconeogenesis (2). Several investigators (2-4) have attempted to prematurely induce hepatic PEPCK specific activity and gluconeogenesis in vivo in the fetus. However, despite induction of hepatic cytosolic PEPCK specific activity and mRNA accumulation, significant fetal glucose production has rarely been demonstrated until very close to term, coincident with large increases in cortisol production by the fetal adrenal gland $(2,5)$.

The chronically $\mathrm{HH}$ fetal lamb is a growth-retarded fetus that has been shown to have significant fetal glucose production (6). Because the $\mathrm{HH}$ fetal lamb is growth-retarded and has little hepatic glycogen, this observed fetal glucose production may be due to gluconeogenesis (6). Study of the gluconeogenic potential in such a model is important, as human infants with intrauterine growth retardation are frequently hypoglycemic, and limited gluconeogenesis has been suggested as one possible cause. We designed this study to determine the effect of chronic fetal hypoglycemia and hypoinsulinemia on the specific activities of PEPCK isoenzymes in the liver and kidney and the enzymes FDPase (D-fructose-1,6-bisphosphate 1-phosphohydrolase, EC 3.1.3.11) and G-6-Pase (EC 3.1.3.9) in the liver. We hypothesized that hepatic cytosolic PEPCK specific activity (the rate-limiting enzyme of gluconeogenesis) would be prematurely increased in the $\mathrm{HH}$ fetal lamb.

\section{MATERIALS AND METHODS}

Materials. Chemicals were of highest grade available and were purchased from Sigma Chemical Co. (St. Louis, MO). ${ }^{14} \mathrm{C}$ $\mathrm{NaHCO}_{3}(3.4 \mathrm{mCi} / \mathrm{mmol}$ ) was from New England Nuclear (Boston, MA).

Animal preparation. Experiments were conducted in pregnant Columbia-Rambouillet ewes. The ewes were fasted for $2 \mathrm{~d}$ before surgery. An initial limited surgery was performed at approximately $80 \mathrm{~d}$ of gestation (53\% of gestation) under i.v. pentobarbital $(5.0 \mathrm{mg} / \mathrm{kg})$ or ketamine $(12$ to $15 \mathrm{mg} / \mathrm{kg})$ sedation. Two maternal catheters for infusion were placed into a femoral vein through a left groin incision, and a single catheter for sampling of arterial blood was placed into the femoral artery. At approximately $115 \mathrm{~d}$ of gestational age, a second surgery was performed under i.v. pentobarbital sedation (5 to $15 \mathrm{mg} / \mathrm{kg}$ ) and spinal anesthesia (tetracaine $\mathrm{HCl} 6.0 \mathrm{mg}$ in hypertonic glucose) or with i.v. ketamine (12 to $15 \mathrm{mg} / \mathrm{kg}$ ) and intramuscular acetylpromethazine $(1 \mathrm{mg} / \mathrm{kg})$ anesthesia. After a midline laparotomy, a catheter for sampling uterine venous blood was placed into the main uterine vein draining the pregnant uterine horn. Then, a 
standard hysterotomy was performed, and catheters for fetal infusions were placed into fetal femoral veins via hindlimb pedal veins. Additional catheters for fetal blood sampling were placed into the fetal abdominal aorta via a hindlimb pedal artery and, by a direct method, into the common umbilical vein via one of the two umbilical veins at the base of the umbilical cord. All catheters were tunneled s.c. through a flank incision on the ewe and kept within a plastic pouch attached to the ewe's skin. The catheters were flushed every day with heparinized $0.9 \%$ (wt/vol) sodium chloride (150 U heparin). Each ewe was allowed to recover postoperatively for 2 to $3 \mathrm{~d}$ until behavior, food intake, and water intake were normal. The ewes were kept in carts and given an ad libitum diet of alfalfa pellets, water, and mineral supplements. Intramuscular B-complex vitamins (Vedco, St. Joseph, MO) were given every week to the ewe. The ewes were housed in a room with the temperature controlled between 10 and $20^{\circ} \mathrm{C}$. At least two sheep were always housed together for company $(6,7)$.

Study design. One group of eight ewes was used for control studies (mean gestational age, $133 \pm 3.7 \mathrm{~d}$ ). This group did not receive any i.v. infusions except at the time of study. A second group of nine ewes $(\mathrm{HH}$ : gestational age $136 \pm 2.6 \mathrm{~d})$ received a continuous infusion of insulin i.v. for approximately $8 \mathrm{wk}$ (80 to $135 \mathrm{~d}$ gestational age). Maternal arterial blood was sampled daily or twice daily for measurement of glucose and insulin concentration. The maternal arterial whole-blood glucose concentrations were used to adjust the insulin infusion rate to achieve a desired arterial whole-blood glucose concentration of approximately 1.4 $\mathrm{mmol} / \mathrm{L}(25 \mathrm{mg} / \mathrm{dL})$, representing an estimated reduction of $50 \%$ from normal. After fetal catheterization at $115 \mathrm{~d}$ gestation, it was observed that the maternal hypoglycemia also produced an approximately proportional decrease in fetal glucose and insulin concentrations (6).

Before autopsy, a metabolic study was performed. The maternal insulin infusion to maintain maternal and fetal hypoglycemia at the chronically produced level was continued during the study. Antipyrine was infused by a primed, constant infusion method into the fetus to measure umbilical blood flow by the transplacental steady-state diffusion technique $(8)$. [U- $\left.{ }^{14} \mathrm{C}\right]$-glucose $(332$ $\mathrm{mCi} / \mathrm{mmol}$, ICN Biomedicals Inc., Costa Mesa, CA) was mixed with the antipyrine to deliver a primed constant infusion of tracer glucose to measure fetal glucose utilization (9). After 120 min of infusion, blood was sampled simultaneously from the umbilical arterial and venous catheters at four times separated by $15-$ to 20 -min intervals. This blood was used to measure blood concentrations of glucose, tracer glucose, and antipyrine, blood oxygen saturation and content, and plasma insulin and glucagon concentrations. After metabolic studies, the fetus was delivered by cesarean section with pentobarbital anesthesia $(25$ $\mathrm{mg} / \mathrm{kg}$ ). The ewe was then killed with a rapid i.v. infusion of CII euthanasia solution (Anthony Products, Acadia, CA). The fetal tissues were removed and the fetus was killed by exsanguination.

All aspects of the animal procurement (Nebekar Ranch, Santa Monica, CA), care, surgery, recovery, maintenance, study, and euthanasia were approved by the University of Colorado Health Sciences Center Institutional Animal Care and Use Committee.

Chemical and analytical methods. Whole-blood glucose concentration was measured by a glucose oxidase method (Sigma). Maternal and fetal plasma insulin concentrations were measured by a double antibody method using a kit from Cambridge Medical Diagnostics, Inc. (Billerica, MA) and ovine insulin standards from Eli Lilly (Indianapolis, IN). Interassay and intraassay variability was less than $8 \%$. Maternal and fetal plasma glucagon were determined by RIA, specific for pancreatic glucagon, using a kit from ICN Biomedicals Inc. The intraassay variability was $\pm 8 \%$, and the interassay variability was $\pm 12.5 \%$.

Enzymatic analyses. Cytosolic and mitochondrial fractions were prepared from fresh liver and kidney tissue according to the method of Chang and Lane (10). Mitochondrial contamination of the cytosolic extract was routinely assayed by citrate synthase (11). PEPCK was assayed by the ${ }^{14} \mathrm{C}$-bicarbonate fixation assay of Chang and Lane (10). Results are expressed as nmol of product fixed per min per mg of protein. Maximal FDPase activity was assayed by the method of Mazzotta and Veneziale (12) with results expressed as nmole of product formed per min per $\mathrm{mg}$ of protein. Protein was determined according to the method of Lowry (13) with BSA as the standard. G-6-Pase was assayed on glucose-free crude liver extracts by the spectrophotometric assay of Gierow and Jergil (14). Briefly, after homogenization in $0.35 \mathrm{M}$ sucrose, $10 \mathrm{mM}$ Tris, $\mathrm{pH} 7.4$, the extract was centrifuged at $4000 \times g$ at $4^{\circ} \mathrm{C}$ for $15 \mathrm{~min}$. The endogenous glucose was removed from the supernatant by passage on a Sephadex G25 column (Pharmacia, Piscataway, NJ). Parallel spectrophotometric determinations were performed without the addition of glucose-6-phosphate to confirm the absence of glucose (14). Results are expressed as nmol of product formed per min per $\mathrm{mg}$ of protein, assuming 2 nmole of NADH per nmol of product formed.

Statistics. Values are reported as mean \pm SEM. Differences among groups were analyzed by $t$ test with significance at $p<$ 0.05 .

\section{RESULTS}

Chronic maternal hyperinsulinemic, hypoglycemic clamps resulted in a reduction of mean fetal glucose and insulin concentration compared with control animals (Table 1). As shown in Table 1, the $\mathrm{HH}$ fetal lambs were smaller when compared with control and had reduced liver weight reflecting the intrauterine growth retardation of the $\mathrm{HH}$ fetal lamb. There was a significant reduction in net umbilical glucose uptake in the $\mathrm{HH}$ fetal lambs and a trend toward a lower rate of glucose utilization (Table 2).

Table 1. Fetal growth parameters, blood glucose, and plasma insulin and glucagon levels in control and HH fetal sheep*

\begin{tabular}{lcc}
\hline & Control $(n=8)$ & $\mathrm{HH}(n=9)$ \\
\hline Fetal wt $(\mathrm{g})$ & $3190 \pm 190$ & $2640 \pm 200 \dagger$ \\
Fetal liver wt $(\mathrm{g})$ & $102 \pm 7$ & $76 \pm 7 \dagger$ \\
Mean fetal glucose & $1.19 \pm 0.11$ & $0.51 \pm 0.06$ \\
$\quad[\mathrm{mmol} / \mathrm{L}(\mathrm{mg} / \mathrm{dL})]$ & $(21.9 \pm 1.9)$ & $(9.2 \pm 1.0) \ddagger$ \\
Mean fetal insulin & $86 \pm 16$ & $24 \pm 4$ \\
$\quad[\mathrm{pmol} / \mathrm{L}(\mu \mathrm{U} / \mathrm{mL})]$ & $(12.0 \pm 2.2)$ & $(3.3 \pm 0.6) \dagger$ \\
Fetal plasma gluca- & $208 \pm 62$ & $263 \pm 110$ \\
$\quad$ gon $(\mathrm{ng} / \mathrm{L})$ & &
\end{tabular}

* Insulin and glucagon values are from the day before lambs were killed. All values are mean $\pm \mathrm{SEM}$.

$\dagger p<0.01$ vs control.

$\ddagger p<0.001$ vs control.

Table 2. Metabolic parameters in control and HH fetal lambs*

\begin{tabular}{|c|c|c|}
\hline $\begin{array}{c}\text { Fetal metabolic } \\
\text { parameters }\end{array}$ & Control $(n)$ & $\mathrm{HH}(n)$ \\
\hline $\begin{array}{l}\text { Glucose uptake (mmol/ } \\
\mathrm{kg} / \mathrm{min} \text { ) }\end{array}$ & $0.25 \pm 0.03(6)$ & $0.13 \pm 0.02(9) \dagger$ \\
\hline $\begin{array}{l}\text { Glucose utilization } \\
(\mathrm{mmol} / \mathrm{kg} / \mathrm{min})\end{array}$ & $0.32 \pm 0.04(6)$ & $0.23 \pm 0.04(6)$ \\
\hline $\begin{array}{l}\text { Glucose production rate } \\
(\mathrm{mmol} / \mathrm{kg} / \mathrm{min})\end{array}$ & $0.069 \pm 0.030(6)$ & $0.116 \pm 0.023(6)$ \\
\hline $\begin{array}{l}\text { Arterial } \mathrm{O}_{2} \text { saturation } \\
(\%)\end{array}$ & $53.5 \pm 2.8(4)$ & $54.4 \pm 3.5(9)$ \\
\hline $\begin{array}{l}\text { Arterial } \mathrm{O}_{2} \text { content } \\
(\mathrm{mmol} / \mathrm{L})\end{array}$ & $3.50 \pm 0.21(4)$ & $3.06 \pm 0.28(9)$ \\
\hline $\begin{array}{l}\text { Umbilical } \mathrm{O}_{2} \text { uptake } \\
(\mu \mathrm{mol} / \mathrm{kg} / \mathrm{min})\end{array}$ & $329 \pm 17(4)$ & $361 \pm 17(9)$ \\
\hline
\end{tabular}

* All values are mean \pm SEM. Data available for only six of nine $\mathrm{HH}$ animals for glucose utilization and glucose production rate and four of six controls for $\mathrm{O}_{2}$ saturation, content, and uptake.

$\dagger p<0.05$ vs control. 
Glucose production rate was significantly greater than zero in the $\mathrm{HH}$ fetuses at a rate similar to that reported by us previously using a 2- to 3-wk period of insulin-induced hypoglycemia (6). Glucose production was also greater than zero in the control sheep due to data from two sheep in which glucose utilization rate was unexpectedly high. We do not have an explanation for the results in these two fetuses. Without their data, glucose utilization rate was $0.25 \pm 0.03 \mathrm{mmol} / \mathrm{kg} / \mathrm{min}(4.58 \pm 0.52 \mathrm{mg} /$ $\mathrm{kg} / \mathrm{min}$ ), not different from umbilical glucose uptake, representing a glucose production rate of $0.04 \pm 0.03 \mathrm{mmol} / \mathrm{kg} / \mathrm{min}(0.64$ $\pm 0.49 \mathrm{mg} / \mathrm{kg} / \mathrm{min}$ ), not different from zero $(p>0.05)$.

Cytosolic PEPCK specific activity was significantly higher in the $\mathrm{HH}$ fetal liver as compared with controls. In contrast, there was no difference in the specific activity of mitochondrial PEPCK between the groups (Fig. 1). The hepatic cytosolic PEPCK specific activity in the $\mathrm{HH}$ fetal lambs was similar to that seen in 1wk-old newborn lambs (mean of two values: $19 \mathrm{nmol} / \mathrm{min} / \mathrm{mg}$ protein). Because the liver weight was reduced in the $\mathrm{HH}$ fetal lamb compared with control (Table 1), we compared total hepatic cytosolic PEPCK specific activity (specific activity in $\mu \mathrm{mol} /$ $\mathrm{min} / \mathrm{g}$ liver $\times \mathrm{g}$ total liver $\mathrm{wt}$ ), and there was still a significant increase in the $\mathrm{HH}$ fetuses $(93 \pm 11 \mu \mathrm{mol} / \mathrm{min})$ compared with controls $(26 \pm 12 p<0.01)$.

Cytosolic PEPCK is found in the liver, kidney, and, to lesser degree, in the intestine. Kidney cytosolic PEPCK may contribute to gluconeogenesis, although the hormonal and nutritional regulation of PEPCK in the kidney is different from that of the hepatic isoenzyme $(15,16)$. There was no significant difference in kidney cytosolic PEPCK between $\mathrm{HH}(13.4 \pm 3.1 \mathrm{nmol} / \mathrm{min} /$ mg protein, $n=7)$ and controls $(12.8 \pm 2.1, n=4)$.

Mitochondrial PEPCK is an inner mitochondrial matrix enzyme (17). To confirm that the increase in hepatic cytosolic PEPCK in the HH group was not due to greater mitochondrial contamination in the $\mathrm{HH}$ group compared with control, citrate synthase, an inner mitochondrial matrix enzyme like mitochondrial PEPCK, was used. There was no difference in the percentage of citrate synthase contamination of the cytosolic hepatic fractions in the controls or $\mathrm{HH}$ fetuses $(4 \pm 4 \%$ versus $9 \pm 5 \%)$. Thus, the increase in cytosolic PEPCK specific activity in the $\mathrm{HH}$ fetal lambs cannot be accounted for by an increase in contamination of the cytosolic fraction by the mitochondrial isoenzyme.

G-6-Pase is the last step in hepatic release of glucose. Hepatic G-6-Pase specific activity was not significantly different in the HH animals compared with controls (Table 3).

FDPase has been reported to be increased in fasting and is necessary for gluconeogenesis (18). FDPase specific activity was not significantly different between the $\mathrm{HH}$ and control fetal lambs (Table 3).

Cytosolic PEPCK specific activity and RNA levels are in-

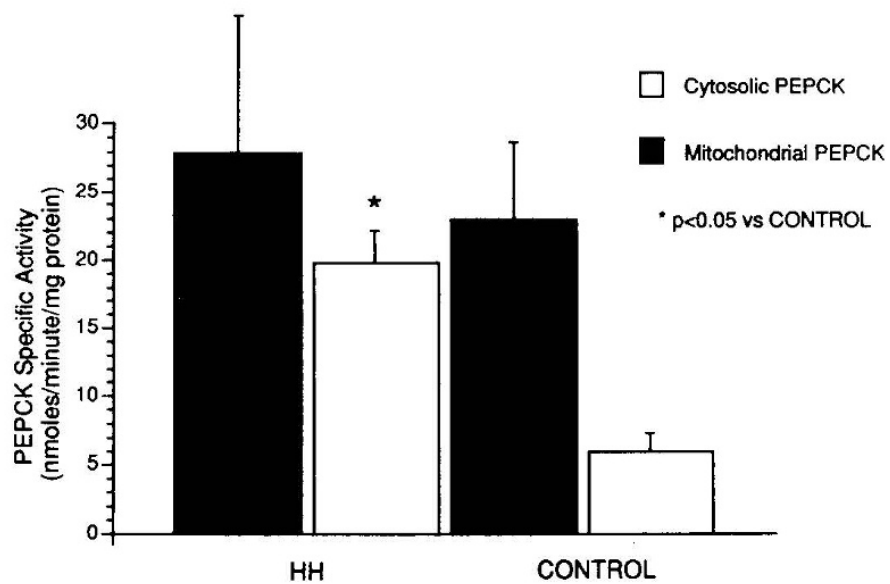

Fig. 1. Comparison of hepatic cytosolic and mitochondrial PEPCK between $\mathrm{HH}$ and control fetal lambs.
Table 3. Effect of chronic fetal hypoglycemia and hypoinsulinemia on fetal hepatic FDPase and G-6-Pase*

\begin{tabular}{lcc}
\hline & Control $(n)$ & HH $(n)$ \\
\hline $\begin{array}{l}\text { Maximal FDPase activity } \\
\text { (nmol/min/mg protein) }\end{array}$ & $19.2 \pm 10.2(5)$ & $39.3 \pm 8.3(9)$ \\
$\begin{array}{l}\text { G-6-Pase }(\mathrm{nmol} / \mathrm{min} / \mathrm{mg} \\
\text { protein) }\end{array}$ & $6.2 \pm 1.4(8)$ & $8.3 \pm 2.1(9)$ \\
\hline
\end{tabular}

* All values are mean $\pm \mathrm{SEM}$.

creased by glucagon and cAMP in the rat and in hepatoma cells $(19,20)$. Thus, plasma glucagon was analyzed to determine whether it correlated with the increase in cytosolic PEPCK specific activity. Plasma glucagon was not significantly different between the two groups (Table 1). The data in Table 1 for plasma glucagon are for the day before killing. If serial plasma glucagon measurements are included from the final 4 wk of the study period, there is still no difference between control $(298 \pm 38 \mathrm{ng} /$ $\mathrm{L}, n=27)$ and $\mathrm{HH}$ lambs $(289 \pm 28 \mathrm{ng} / \mathrm{L}, n=35)$.

\section{DISCUSSION}

The production of chronic hypoglycemia and hypoinsulinemia in the fetal lamb with a chronic maternal hyperinsulinemic, hypoglycemic clamp results in an increase in hepatic cytosolic PEPCK specific activity to levels found in the 1-wk-old lamb but no changes in G-6-Pase or FDPase activity. The results of this study are in contrast to the results of Gruppuso et al. $(21,22)$ in fetal rats. In their studies, chronic $\mathrm{HH}$ fetal rats did not have an increase in hepatic PEPCK activity. There was an increase in G6-Pase activity in one study (22) but not in the other (21). Girard et al. $(4,23)$ have demonstrated an increase in PEPCK in the rat fetuses of fasted, hypoglycemic mothers or phloridzin-treated, hypoglycemic mothers. The specific activity of PEPCK in these studies was still low $(1.7 \mathrm{nmol} / \mathrm{min} / \mathrm{mg}$ protein and $5.4 \mathrm{nmol} /$ $\mathrm{min} / \mathrm{mg}$ protein, respectively) compared with the levels in this study. Because the specific activity of hepatic cytosolic PEPCK is similar to that found in the 1-wk-old lamb and the 1-wk-old lamb has significant gluconeogenic potential, the enzymatic potential for gluconeogenesis exists in the $\mathrm{HH}$ fetal lamb, and the fetal glucose production observed in late gestation in the $\mathrm{HH}$ fetal lamb may be due to gluconeogenesis (5).

The mechanism of the up-regulation of hepatic cytosolic PEPCK in the HH fetal lamb is less clear. Glucagon, via its second messenger, cAMP, has been shown to increase hepatic cytosolic PEPCK specific activity, mRNA, and transcription rate in adult, late gestation fetal, and cultured adult rat hepatocytes (19). However, the effect of prenatal administration of glucagon to neonatal rats is dependent upon the gestational age. Before 18 $\mathrm{d}$ of gestation, there is no effect of glucagon on hepatic cytosolic PEPCK specific activity or mRNA steady state levels (24). After $18 \mathrm{~d}$, PEPCK specific activity and mRNA are induced; however, fetal gluconeogenesis has not been demonstrated (24). In cultured fetal rat hepatocytes, glucagon or cAMP can increase PEPCK activity and mRNA as early as $14 \mathrm{~d}$ of gestation (25). However, because the fetal hepatocyte undergoes rapid maturation in culture, this may not reflect the situation in vivo. The fetal lamb has been reported to be insensitive to glucagon (26). However, studies supporting this observation were performed in the normal fetus, and not under conditions of chronic hypoglycemia and/or hypoinsulinemia, as observed in the $\mathrm{HH}$ fetal lamb. The lack of a difference in plasma glucagon concentrations between control and $\mathrm{HH}$ lambs would support the hypothesis that there is no direct relationship between plasma glucagon and cytosolic PEPCK induction in the fetal lamb liver in this model. Girard et al. (27) have suggested that the regulation of the induction of gluconeogenesis at birth is due to a decrease in the insulin to glucagon ratio. This would suggest that insulin and glucagon balance, not the absolute value of the individual hormones, might be important in the regulation of gluconeogenesis and cytosolic 
PEPCK. There was a decrease in the insulin:glucagon molar ratio in the HH group. However, because this decrease was due solely to the decrease in plasma insulin in the $\mathrm{HH}$ animals, we were unable to separate the effect of hypoinsulinemia alone from that of the decrease in the insulin to glucagon ratio on cytosolic PEPCK. Evidence for the importance of the insulin:glucagon ratio and fetal glucose production also comes from other studies in fetal sheep in which insulin-regulatable glucose production was observed in fetal sheep made hypoinsulinemic but hyperglucagonemic by streptozotocin (28). In contrast, a much lower, almost negligible rate of glucose production was observed in fetal sheep made hypoinsulinemic but normoglucacgonemic by pancreatectomy (29). Thus, in conditions with a low insulin to glucagon molar ratio, as in this model, fetal glucose production has been demonstrated (28). Future studies will need to address the mechanism of this increase in PEPCK in the chronically $\mathrm{HH}$ fetal lamb. One such mechanism might involve regulation by corticosteroids. Dexamethasone has been shown to increase cytosolic PEPCK activity and mRNA in vivo and in vitro (30-32), although this is controversial (25). Because the HH fetal lamb may be a stressed animal, it is possible that the induction of cytosolic PEPCK in these animals is in part due to an increase in corticosteroid secretion. Indeed, studies by Townsend et al. (5) and Fowden et al. (33) have demonstrated the importance of cortisol in promoting the capacity for glucose production in the late gestation fetal sheep.

Previous studies in the rat have suggested that fetal hypoinsulinemia and hypoglycemia can induce G-6-Pase specific activity (22); but this has not been a consistent finding (21). Our data for G-6-Pase are similar to the first study of Gruppuso et al. (21) in fetal rats. They found no effect of chronic maternal hyperinsulinemia/hypoglycemia on fetal hepatic G-6-Pase levels. Indeed, the level of hepatic G-6-Pase in the late-gestation fetal lamb is close to the level in the postnatal lamb and is most likely sufficient for glucose release from the liver.

In conclusion, we have demonstrated the premature induction of hepatic cytosolic PEPCK in the HH fetal lamb. We suggest that the enzymatic requirements for fetal gluconeogenesis are present in the $\mathrm{HH}$ fetal lamb, and that gluconeogenesis may account for the fetal glucose production of the $\mathrm{HH}$ fetal lamb. The chronically $\mathrm{HH}$ fetal lamb may provide a model to study the ontologic regulation of hepatic cytosolic PEPCK and factors regulating fetal gluconeogenesis.

Acknowledgments. The authors thank Susan Anderson, Karen Briggs, and Gayle Jones for providing excellent technical support.

\section{REFERENCES}

1. Warnes DM, Seamark RF, Ballard FJ 1977 Metabolism of glucose, fructose and lactate in vivo in chronically cannulated foetuses and in suckling lambs. Biochem J 162:617-626

2. Girard J 1986 Gluconeogenesis in late fetal and early neonatal life. Biol Neonate 50:237-258

3. Kliegman RM, Miettinen EL, Adam PAJ 1981 Fetal and neonatal responses to maternal canine starvation: circulating fuels and neonatal glucose production. Pediatr Res 15:945-951

4. Girard JR, Ferre P, Gilbert M, Kervran A, Assan R, Marliss EB 1977 Fetal metabolic response to maternal fasting in the rat. Am J Physiol 232:E456E463

5. Townsend SF, Rudolph CD, Wood CE, Rudolph AM 1989 Perinatal onset of hepatic gluconeogenesis in the lamb. J Dev Physiol 12:329-335

6. DiGiacomo JE, Hay Jr WW 1990 Fetal glucose metabolism and oxygen consumption during sustained hypoglycemia. Metabolism 39:193-202

7. DiGiacomo JE, Hay Jr WW 1989 Regulation of placental glucose transfer and consumption by fetal glucose production. Pediatr Res 25:429-434
8. Meschia G, Cotter JR, Breathnach CS, Barron DH 1967 Simultaneous measurement of uterine and umbilical blood flows and oxygen uptakes. Q J Exp Physiol 52:1-18

9. Hay Jr WW, Sparks JW, Quissell BJ, Battaglia FC, Meschia G 1981 Simultaneous measurements of umbilical uptake, fetal utilization rate and fetal turnover rate of glucose. Am J Physiol 240:E662-E668

10. Chang HC, Lane MD 1966 The enzymatic carboxylation of phosphoenolpyruvate. J Biol Chem 241:2413-2420

11. Shepherd D, Garland PB 1969 Kinetic properties of citrate synthase from rat liver mitochondria. Biochem J 114:597-610

12. Mazzotta MY, Veneziale CM 1980 Concentration of liver and kidney fructose1,6-diphosphatase determined by specific radioimmunoassay. Biochim Biophys Acta 611:156-167

13. Lowry OH, Rosebrough NJ, Farr AL, Randall RJ 1951 Protein measurement with the Folin phenol reagent. J Biol Chem 193:265-275

14. Gierow P, Jergil B 1980 A spectrophotometric method for the determination of glucose-6-phosphatase activity. Anal Biochem 101:305-309

15. Watford M, Mapes RE 1990 Hormonal and acid-base regulation of phosphoenolpyruvate carboxykinase mRNA levels in rat kidney. Arch Biochem Biophys 282:399-403

16. Nelson K, Cimbala MA, Hanson RW 1981 Regulation of the turnover of the mRNA for hepatic phosphoenolpyruvate carboxykinase (GTP). In: Veneziale CM (ed) The Regulation of Carbohydrate Formation and Utilization in Mammals. University Park Press, Baltimore pp 349-392

17. Hod Y, Utter MF, Hanson RW 1982 The mitochondrial and cytosolic forms of avian phosphoenolpyruvate carboxykinase (GTP) are encoded by different messenger RNAs. J Biol Chem 257:13787-13794

18. Pontremoli S, Melloni E, Salamino F, DeFlora A, Horecker BL 1974 Changes in activity and molecular properties of fructose-1,6-bisphosphatase during fasting and refeeding. Proc Natl Acad Sci USA 71:1776-1779

19. Granner DK, Sasaki K, Chu D 1986 Multihormonal regulation of phosphoenolpyruvate carboxykinase gene transcription. Ann NY Acad Sci 478:175190

20. Gunn JM, Tilghman SM, Hanson RW, Reshef L, Ballard FJ 1975 Effects of cyclic adenosine monophosphate, dexamethasone and insulin on phosphoenolpyruvate carboxykinase synthesis in reuber $\mathrm{H}-35$ hepatoma cells. Biochemistry 14:2350-2357

21. Gruppuso PA, Migliori R, Susa JB, Schwartz R 1981 Chronic maternal hyperinsulinemia and hypoglycemia. Biol Neonate 40:113-120

22. Domenech M, Gruppuso PA, Susa JB, Schwartz R 1985 Induction in utero of hepatic glucose- 6 -phosphatase by fetal hypoinsulinemia. Biol Neonate 47:92-98

23. Freund N, Kervan A, Assan R, Geloso JP, Girard J 1980 Fetal metabolic response to phloridzin-induced hypoglycemia in pregnant rats. Biol Neonate 38:321-327

24. Benvenisty N, Cohen N, Gidoni B, Mencher D, Meyuhas O, Shouval D, Reshef L 1984 Insulin-deficient diabetes in the perinatal period: ontogeny of gluconeogenesis and phosphoenolpyruvate carboxykinase. In: Shafrir E, Renold A (eds) Lessons from Animal Diabetes. Libbey, London, pp 717-733

25. van Roon MA, Zonneveld D, Charles R, Lamers WH 1988 Accumulation of carbamoylphosphate-synthetase and phosphoenolpyruvate-carboxykinase mRNA in embryonic rat hepatocytes. Eur J Biochem 178:191-196

26. Devaskar SU, Ganguli S, Styer D, Devaskar UP, Sperling MA 1984 Glucagon and glucose dynamics in sheep: evidence for glucagon resistance in the fetus. Am J Physiol 246:E256-E265

27. Girard JR, Ferre P, Kervran A, Pegorier JP, Assan R 1977 Role of the insulin/ glucagon ratio in the changes of hepatic metabolism during development of the rat. In: Foa PP, Bajaj JS, Foa NL (eds) Glucagon: Its Role in Physiology and Clinical Medicine. Springer-Verlag, New York, pp 563-581

28. Hay Jr WW, Meznarich HK, Fowden AL 1989 The effects of streptozotocin on the rates of glucose utilization, oxidation, and production in the sheep fetus. Metabolism 38:30-37

29. Fowden AL, Hay Jr WW 1988 The effects of pancreatectomy on the rates of glucose utilization, oxidation and production in the sheep fetus. Q J Exp Physiol 73:973-984

30. Hoppner W, Sussmuth W, O'Brien C, Seitz HJ 1986 Cooperative effect of thyroid and glucocorticoid hormones on the induction of hepatic phosphoenolpyruvate carboxykinase in vivo and in cultured hepatocytes. Eur $\mathrm{J}$ Biochem 159:399-405

31. Narkewicz MR, Iynedjian PB, Ferre P, Girard J 1990 Insulin and triiodothyronine induce glucokinase $\mathrm{mRNA}$ in primary cultures of neonatal rat hepatocytes. Biochem J 271:585-589

32. van Roon MA, Charles R, Lamers WH 1987 Synthesis, accumulation and turnover of carbamoylphosphate synthetase and phosphoenolpyruvate carboxykinase in cultures of embryonic rat hepatocytes. Eur J Biochem 165:229-234

33. Fowden AL, Coulson RL, Silver M 1990 Endocrine regulation of tissue glucose6-phosphatase activity in the fetal sheep during late gestation. Endocrinology 126:2823-2830 